\title{
Agents in the sporting field: a law and economics perspective
}

\author{
William Bull ${ }^{1} \cdot$ Michael Faure $^{1}$
}

Accepted: 10 July 2021 / Published online: 28 July 2021

(c) The Author(s) 2021

\begin{abstract}
While agents have been active in the sporting field since the late 1800s, sports agents and their activities have grown in prominence only in more recent times, particularly as a result of typically adverse headlines. Agents are generally considered to be necessary (or some might say a necessary evil) for the sporting industry, in the representation of sportsmen and women, the consultation of sports clubs and franchises, or the facilitation of employment contracts and transfer deals. In contrast to players and clubs (not to mention sports federations and governing bodies), however, sports agents are not engaged in sporting endeavour. Rather, the essence of their role is an economic one for the provision of services. This peripheral position of sports agents implies that their interests are likely to be quite different from those of other stakeholders in the sports industry - but it also gives rise to a significant regulatory conundrum. This conundrum has become especially apparent in the sport of football in recent years, where various attempts at regulation of access to and the performance of the profession of football agent have been made at national and international level. The field of sports and football in particular clearly has a great societal impact and a large economic value. Yet, sports law is remarkably absent so far from the economic approach to law. From a law and economics perspective and in the light of regulation theory, therefore, our main research questions are whether there is a need to regulate the profession of sports agent and, if so, what type of regulation is needed.
\end{abstract}

Keywords Agency problem $\cdot$ Contract regulation $\cdot$ Asymmetric information $\cdot$ Adverse selection $\cdot$ Externalities $\cdot$ Regulatory models

\section{Introduction}

The sports agent is an inconspicuous but influential animal. Little known and yet much maligned, agents are an integral, if incidental, part of professional sport. While agents have been active in the sporting field since the late 1800 s, the role they play and the functions they perform remained relatively recondite for the best part of a century. More recently, however, sports agents and their activities have grown in prominence. ${ }^{1}$ In tandem with ever-increasing professionalization, commercialization and globalization of sport, the prevalence of sports agents has also increased, to the point that their profession has started to come under the spotlight. Particularly in the footballing world, but also

William Bull

william.bull@maastrichtuniversity.nl

Michael Faure

michael.faure@maastrichtuniversity.nl

1 Faculty of Law, Maastricht University, P.O. Box 616, 6200 MD Maastricht, The Netherlands in sports such as basketball, ice hockey, rugby, and athletics, to name but a few, sports agents have begun to enter the public psyche, not least as a result of typically adverse headlines, reportages and exposés concerning lucrative remuneration, undeclared payments, conflicts of interest, clandestine approaches, exploitation and corruption. Of course, topical issues of this nature pervade the sporting sphere and have involved many different actors that operate therein, ranging from individual players and clubs all the way up to sports governing bodies and international sports federations; but agents seem to be widely viewed almost as a physical embodiment of these problems afflicting the realm of professional sport. Nevertheless, agents are also generally considered to be necessary (or some might say a necessary evil) for the sporting industry. ${ }^{2}$ Whether it is in the representation of sportsmen and women, the consultation

\footnotetext{
${ }^{1}$ For a historical overview of the development of the agent's industry in the sport of football, see Rossi 2019, pp. 131-138, and also Rossi et al. 2016, pp. 1-21.

2 On this, see Shropshire and Davis 2008, p. 12 (and the rest of chapter 1 regarding the history of the sports agents profession more generally).
} 
of sports clubs and franchises, or the facilitation of employment contracts and transfer deals, agents have become a kind of "hydraulic fluid" coursing through the labour and transfer markets of the sporting sector. In the course of their careers, sports agents may be required by players and/or clubs to act as negotiators, advisors, scouts, career managers, administrators, public relations officers or even lawyers, and may even perform any number of these functions simultaneously. In this sense, and for the purpose of this contribution, sports agents may be defined broadly as natural or legal persons contracted by athletes or sporting enterprises to act on their behalf, particularly (but not necessarily only) in dealing with third parties. Through the investment of considerable time and financial resources, sports agents need to acquire vast and varied expertise, competences and relational networks in order to successfully deliver the service that they offer, which those that they serve simply do not possess.

Sports agents have been subject to a great deal of legal rules, especially since the turn of the century. Some of those (like the rules of the international governing body, the Fédération Internationale de Football Association, or FIFA) are private standards, whereas in some countries sports agents are regulated by domestic law (either private and/or public law) as well. ${ }^{3}$ Moreover, to a large extent the standards applicable to these agents are of a hybrid nature, meaning private as well as formal standards apply at the same time. Furthermore, there can be large differences between countries in terms of the way in which sports agents are regulated. Not only do some countries (like England) tend to largely rely on private standards and laws, whereas others (like France) rely more on codified sports laws, but the content of the applicable standards can also vary widely. In some cases mere (private law) information duties or conduct regulations apply, whereas under other regimes the access to the profession of sports agent is regulated as well (which could be via licensing or, alternatively, registration). Already in view of this wide variety in the types of regulation that have been adopted in respect of the profession, sports agents are an interesting topic of research given the large interests of law and economics in the regulation of professions generally. ${ }^{4}$

The field of sports, and particularly football (or soccer), clearly has a great societal impact and a large economic value. Yet, in contrast to other specialized areas of law such as media law, environmental law and consumer law, sports law is remarkably absent so far from the economic approach to law. We will argue in this paper that the case of sports agents provides an interesting opportunity to test various paradigms of the economic analysis of law. We will equally argue that the insights from the rich law and economics

\footnotetext{
3 See further section 4.

${ }^{4}$ See Faure et al. 1993.
}

literature can be used to answer some of the questions which are now at the core of the policy debate related to the role of football agents, and especially whether there is a particular need for regulating access to and the exercise of their profession and if so, what form such regulation should take. Our main research questions to be elaborated in the paper therefore consist of: (1) is there a need to regulate the profession of sports agents and (2) (if so) what type of regulation is needed, specifically in the case of football agency?

Being, to the best of our knowledge, one of the first to address the profession of football agents and their overarching regulation from a law and economics perspective, this contribution is rather explorative in nature. We aim to sketch the roles and functions of sports agents and we map the various questions that can arise in that respect. Rather than aiming at providing definitive answers, we endeavour to contribute to an agenda-setting for further research into this fascinating domain.

In the paper we proceed as follows: after an introduction (1) we present some stylized facts on the functions of football agents and their particular role in the transfer market, explaining the role of sports agents in reducing search and transaction costs, given the information asymmetry between players and clubs (2). Next, we address the question of whether there is any need to regulate the profession of football agents in the light of regulation theory. More specifically, we analyse whether there may be certain market failures in the industry of sports agency (adverse selection, information asymmetries, negative externalities or restrictions of competition), which may provide an economic justification for regulation (3). Assuming that that question is answered positively, we proceed by reviewing a variety of possible instruments of regulation of the profession of football agents (entry requirements, private and public regulations and laws, codes and rules of conduct). In this respect we focus, on the one hand, on some current regulations and their contents and, on the other hand, on different regulatory options available in the light of the law and economics literature (4). Section 5 concludes.

Differently to in an inductive economic approach, we do not attempt to sketch whether and how sports agents should be regulated from an economic point of view (for example via formal economic modelling). Instead, we start from sketching the role and functions of sports agents, and subsequently the nature and contents of the regulation of the football agent's profession at different levels, seeking to analyse the extent to which this can be understood from a law and economics perspective. Our goal is obviously not to normatively assess whether a particular regulation in a specific country would be "better" than another: Those types of comparative endeavours might be interesting avenues for further research. 


\section{The role and functions of sports agents}

\subsection{Background}

In recent times, the issue of the role played by sports agents and the regulation of their profession has been the subject of much and increasing attention and discussion, especially in the game of football. Agents have been involved in the football industry since the onset of professionalism, but their activity has elevated and expanded exponentially in the past few decades. ${ }^{5}$ The rapid growth of popularity and media interest in modern-day football and the concomitant upsurge of revenues flowing into the sport have multiplied and inflated the commercial opportunities in the football market, rendering it an ever more attractive one for agents to seek to exploit. Coupled with a growing internationalization of the sport, with football clubs increasingly looking for new talents in foreign leagues to satisfy their sporting needs (a move made easier by the relaxation of restrictions on the number and transfer of foreign players ${ }^{6}$ ), this has resulted in a market where agents are an "increasingly indispensable accompaniment" to the negotiation and conclusion of contracts between football players and clubs, not to mention between clubs themselves. ${ }^{7}$ According to a seminal empirical study of the football market by Poli, between 1994 and 2009 the number of football agents rose by around 1,000 every year in Europe alone ${ }^{8}$; and, as others have observed, since 2013 just under half of all international football transfers where a transfer fee was paid involved at least one agent acting on behalf of one of the clubs or the player concerned. ${ }^{9}$ In contrast to players and clubs (not to mention sports federations and governing bodies), however, sports agents are not engaged in sporting endeavour, or at least that is not their main goal. Rather, agents operate in the shadow of sporting activity; the essence of their role is an economic one for the provision of services. ${ }^{10}$

\footnotetext{
${ }^{5}$ See Rossi 2019, pp. 131-138, and also Rossi et al. 2016, pp. 1-21.

6 This development has taken place in different countries, and particularly in Europe since the landmark ruling of the European Court of Justice in Bosman in 1995; Case C-415/93 Union Royale Belge des Sociétés de Football Association ASBL v Jean-Marc Bosman [1995] ECR I-04921.

7 Schimke 2007, p. 58.

${ }^{8}$ See Poli 2010.

9 See Ioannidis 2019, p. 154, 158; De Marco and Lowen 2018, p. 213 . It should be added, however, that only around $20 \%$ of all international transfers of male professional players, i.e. including those where a transfer fee was not paid, involve at least one agent. See for example the most recent FIFA report on Intermediaries in International Transfers of 2020.

10 Admittedly, professional sport is also a commercial activity, insofar as players, clubs and sporting authorities may be considered as workers, businesses and associations, respectively; but, these actors have a special status by virtue of the fact that the "work" they per-
}

The modern sports agent may provide a variety of services and, in so doing, fulfil a number of functions, not only for the sportsmen and women whom he or she represents, but also for the sport(s) in which he or she operates. In order to describe the role of sports agents-and in turn to demonstrate the functions of sports agency-it is useful to seek to categorize the football agent's activities, and particularly to distinguish their role in the transfer and employment of professional footballers from other tasks that they commonly carry out. Admittedly, being a rather fluid and indefinite position, it is difficult to dissect and anatomize the job of the sports agent with a large degree of precision. Nevertheless, it is possible to group the different duties that these agents can typically discharge around certain areas of activity. In what follows, each of these core areas of activity of modern sports agents will be discussed, focusing on agents in the football industry. Of course, much of this discussion applies equally to other sports, but given the especial importance of football and its allure for persons offering agency services, it serves as a prime source of examples and illustrations of the roles that agents can play.

\subsection{An intermediary on the transfer market}

Foremost among the football agent's areas of activity, particularly in the modern era, is that of facilitating transfers of players between clubs and the conclusion of transfer contracts. This was not always the case; in fact, after the professionalization of football, agents were initially enlisted by football clubs to act as scouts, in order to identify players that clubs might eventually wish to recruit. ${ }^{11}$ However, as clubs later moved to construct their own internal scouting structures, so agents began to look for other roles in the industry. ${ }^{12}$ This search eventually led agents instead to work primarily for players, who had limited bargaining power in the transfer market, as well as limited control over and influence on the contractual terms governing their employment, which tended to favour the clubs for whom they played. ${ }^{13}$

Over the course and particularly in the latter half of the twentieth century, agents increasingly shifted to the representation of football players, in conjunction with the professionalization of the sport and the liberalization of the labour and transfer market, both within the domestic context

\footnotetext{
Footnote 10 (continued)

form or the "business" with which they deal involves the participation in, and organization of, professional sport and national or international sporting tournaments, which also serves an important public function as a form of entertainment.

11 See Rossi 2019, p. 132; Semens and Pendlebury 2013, p. 528.

12 Ibid.

${ }^{13}$ See Semens and Pendlebury 2013, p. 529.
} 
of national leagues ${ }^{14}$ and, subsequently, on a global level. ${ }^{15}$ Particularly in the European context, the Bosman ruling of the European Court of Justice in the $1990 \mathrm{~s}^{16}$, which enabled players in the EU to transfer to another club without a fee at the end of their contracts while at the same time prohibiting the quota restrictions on foreign players that previously applied to clubs in the EU, gave players more freedom to move between clubs, and created more incentives for clubs to either sell players while still under contract or to offer players approaching the expiry date of their contracts new and improved terms in order to retain them. ${ }^{17}$ Coupled with the earning potential from broadcasting and sponsorship, these developments served to strengthen the position of players (or at least the more sought after players) in their relations with clubs, and to increase their potential to attract higher transfer fees and to achieve higher salaries, thereby creating lucrative commercial opportunities for players to seek to exploit, and in turn for agents to offer their services to assist them in doing so. Accordingly, agents began to carve out a role as middlemen between players and clubs in the transfers of the former between the latter, in return for remuneration, which can be the most lucrative of their careers. In the words of a study commissioned by the European Commission in 2009, "sports agents act, first and foremost, as intermediaries between sportspersons and sports clubs...They bring together the parties interested in concluding an agreement concerning the practice of a sport as a remunerated activity. Finding a job placement for a sportsperson is the central and specific role of sports agents". ${ }^{18}$

Obviously the increased earnings of players in the top tier of professional leagues entailed that these players then had the means to employ agents to act as their representatives in transfer talks with clubs, but they also had good reason to call on the assistance of agents for their career moves. In order to capitalize on their increased leverage over clubs and to maximize their earning potential, knowledge of the transfer market and the ability to obtain a sufficient amount of information about buyers, sellers and fees relatively quickly was required-and knowledgeable middlemen with wellestablished social networks were in a position to provide this. Hence, agents may be used by players in particular,

\footnotetext{
14 In England, for example, the abolition in the 1960s of the so-called retain and transfer system, under which the club with which a player was registered could exert a large degree of control over their movement, was an important milestone in the liberalization of the English labour and transfer market: see Rossi 2019, p. 133, and in more detail on the 'retain and transfer' system notably Magee 2002.

15 See Rossi 2019, p. 133.

16 Case C-415/93 Union Royale Belge des Sociétés de Football Association ASBL v Jean-Marc Bosman [1995] ECR I-04921.

17 See Rossi 2019, p. 134.

18 KEA - CDES 2013, p. 3.
}

in order to make their availability or indeed their abilities known to clubs that were not aware thereof or, where a club is already interested in a certain player, to represent the player's interest (or otherwise) in and propensity to agree (or not) to a certain transfer, prior to the initiation of formal negotiations. ${ }^{19}$ Unless the player is already a 'free agent' as it were (in the sense that their existing employment contract has already expired, or is about to expire), it will be necessary for the club that is interested in signing them to enter into negotiations on and eventually conclude a transfer agreement with their current club (and particularly to agree on a transfer fee), before formal contract negotiations with the player can be initiated. And agents can perform a function here too, in fact, insofar as they may also be used by clubs to act on their behalf in the negotiation of a transfer of a player, including notably the transfer fee to be paid by the buying club to the selling club. ${ }^{20}$ Indeed, even though clubs have continued to have greater access to information and contacts relative to players, they may still see value in enlisting agents to broker transfer deals rather than doing this themselves, as the specialist knowledge and contacts agents can possess often put them in a better position to make connections between parties and to negotiate deals, thereby facilitating the speed and efficiency of player transfers. ${ }^{21}$ From a broader perspective, therefore, agents have identifiable functions in the transfer market as a whole.

\subsection{A representative in contract negotiations}

After a player transfer between clubs has been agreed in principle-or if the player is a free agent-it is still necessary for the player to settle personal terms with the acquiring club before the transfer can be finalized; in other words, an employment contract must be concluded. The negotiation of employment contracts (and eventually their renewal) on behalf of players is another key role performed by agents. Indeed, this corresponds with FIFA's definition of intermediaries as ' $[\mathrm{a}]$ natural or legal person who, for a fee or free of charge, represents players and/or clubs in negotiations with a view to concluding an employment contract or represents clubs in negotiations with a view to concluding a transfer agreement. ${ }^{22}$ In view of the business experience and resources at the disposal of clubs, which are generally superior to those of players, most players are faced with a situation of information asymmetry in their dealings with clubs. As a result, players typically require professional

\footnotetext{
19 See Semens and Pendlebury 2013, p. 531.

20 See Semens and Pendlebury 2013, p. 534.

21 Ibid.

22 FIFA Regulations on Working with Intermediaries 2015, Definition of an intermediary.
} 
representation for the purpose of concluding an employment contract with a club, in order to redress this imbalance in knowledge and power.

Of course, it may be that a player prefers to bargain with a club themselves, and indeed for many years most athletes were reluctant to allow a third party to negotiate on their behalf-in fact some were vehemently opposed to the idea. ${ }^{23}$ However, in the strive to maximize their wages and other contractual benefits, athletes will invariably be better off seeking the specialist advice and service of an agent. As Smienk puts it, "[t]he service of contract negotiation is valuable for almost every athlete, because most athletes have little experience with negotiations and have no business background". ${ }^{24}$ In contrast to most players, professional agents have general business experience as primarily economic actors, as well as specialist experience in the bargaining process, comparable to those who negotiate for clubs. More specifically, a competent agent will usually be more familiar with hidden information about the employment conditions of other players than their clients are, having previously acquired such information at significant expense in terms of time and money (i.e. search costs). This includes not only existing pay structures but also bonuses and other benefits, not to mention release clauses and the like, as well as market conditions more generally. The costs of acquiring this information would otherwise be incurred by the players, who instead are freed up to concentrate on their profession without distractions of this kind. For their part, armed with such knowledge, the agent has more capacity to achieve greater advantages and better conditions for the player they represent, while at the same time remaining within the confines of what is realistically attainable for that player so that an agreement can be reached and the deal can go through.

Furthermore, agents also have a so-called insulating function in this respect; that is, the function of insulating players from the travail of contract negotiations, which could have spillover effects on the player's performance on the pitch. ${ }^{25}$ For if a player chooses to self-negotiate, even if they are competent negotiators themselves, they run the risk of entering into direct confrontation with the club, which may turn out to hamper the player's working (and possibly even personal) relationship with the club's management after the player joins the club (assuming the negotiations are ultimately successful). And, in any event, in the course of the negotiations the player is likely to be confronted with critiques of their value and abilities, since this is a normal strategy for club management representatives in the bargaining

\footnotetext{
${ }_{23}$ See Crandall 1981, p. 815, 816.

24 Smienk 2009, p. 70, 76.

25 See Smienk 2009, p. 70, 76, and also Semens and Pendlebury 2013, p. 535.
}

process, as a counterweight to the arguments that may be put forward to support the case for a higher level of remuneration for the player. ${ }^{26}$ Being aware of critical viewpoints of the club's management could also have a negative influence on the player's subsequent performance, and especially when it comes to a sport like football, where players need to become and operate as a member of a team. For this reason, while it may be less well known, the agent's function as a buffer between the parties and filter of contractual discussions is a crucial one in the eyes of many authors on sports agents. According to Shropshire and Davis, for example, "[i] $\mathrm{n}$ addition to the need for 'expertise' and 'tactical flexibility', the avoidance of confrontation is particularly applicable in the sports setting". 27

\subsection{Other services}

It is also important to recognize that, beyond their core role as brokers and negotiators in the context of the transfer market and player contracts, the modern sports agent often provides other services to players as well. Not least among these are personal services, in the sense of assistance with players' additional needs. These may include anything from making arrangements to satisfy players' basic needs (including housing, transportation, medical services, insurance, administration and even schooling for players' children, etc.) to performing off-the-field duties directly related to the player's profession and status (such as public relations, fan liaison, social media management). ${ }^{28}$ This personal assistance role may be viewed as an extension of the agent's function of ensuring that the player is able to focus on performing, by taking care of ancillary matters on their behalf. In addition, an agent may well be called upon to act in an advisory capacity, providing financial, fiscal and even legal advice (albeit the latter through a legal professional, unless the agent is a qualified lawyer themselves). Once again, the limited time and experience of most players makes this a probability, as professional advice can enable them to adequately and efficiently evaluate different possible options available to them, in what is an increasingly commercial environment with huge amounts of money involved. ${ }^{29}$ Furthermore, players (and particularly the more celebrated ones) frequently need agents to act on their behalf in commercial dealings external to their contract of employment, such as sponsorship, advertising and endorsement deals with national and multinational corporations. Here too the agent has a role in

\footnotetext{
${ }^{26}$ See Shropshire and Davis 2008, p. 24.

27 Ibid.

28 See Semens and Pendlebury 2013, p. 535.

29 See Semens and Pendlebury 2013, pp. 535-536.
} 
finding and negotiating possible contracts that are suitable for the player's status and career.

\subsection{Economic rationale}

From the preceding sketch of their functions and roles, it is clear that sports agents in the modern era of football (and indeed sport in general) can and do play a variety of roles in both the personal and professional lives of athletes, as well as in the recruitment operations of clubs. In so doing, agents fulfil a number of different functions, particularly in the transfer market, as well as in the working and sporting relationship between players and clubs. They have emerged as an important, if not indispensable, actor for players in reducing transaction costs and remedying information asymmetries in their dealings with clubs, so as to take better advantage of the strengthened bargaining position in which they now find themselves, for the enlargement of their career earnings and the enhancement of their career opportunities.

The athlete-agent relationship is a classic case where different economic arguments can be made as to why athletes would engage a sports agent rather than performing particular tasks themselves. The most important argument is obviously that in many aspects athletes are so-called one-shotters (for example in negotiating a contract with a sponsor), whereas the sponsor may be a 'repeat-player', as a result of which the athlete may be in a disadvantaged position. ${ }^{30}$ Since the agent is likely to have more experience in negotiating contracts (for example with a sponsor), he may well have superior information by being a repeat-player himself, and therefore, the capacity to cure the information asymmetry for the athlete. Opportunity costs for athletes to deal with a variety of financial, fiscal and other issues may be huge and could lead to high transaction costs, as athletes often perform in countries where they have little if any knowledge about the domestic regulation. From their perspective, involving an agent to provide brokerage, representative and advisory services therefore lowers both information and transaction costs. These advantages of involving an agent are especially clear when it comes to the moment that an athlete becomes active on the transfer market. Again, the agent may have superior information on potential clubs that might be interested in the athlete; they may be in a better position to make the specific abilities of the athlete known to potentially interested clubs; and they have superior information on what other clubs may pay and what other athletes may earn. Thus, the agent is in a better position to negotiate potential a transfer and contractual terms for his client with a club. All of those advantages emerge as the agent may have

\footnotetext{
30 See on the difference between so-called one-shotters and repeatplayers the classic paper by Galanter 1973 .
}

superior information by being a repeat-player. Furthermore, involving an agent to negotiate on their behalf has the important insulating function for the athlete, thereby avoiding that the relationship with the club would be jeopardized from the start if the athlete were to do the negotiations themselves.

Interestingly, some of the advantages are clearly to the benefit of the player (more particularly when the agent performs a wide variety of administrative services), but to some extent involving an agent may be beneficial to the clubs in the transfer market as well. The higher degree of expertise and experience of the agent may facilitate the negotiations with the new club, but also between the old and the acquiring club, for example concerning a transfer fee. It is for that reason that, as we sketched, historically agents first acted as scouts for the football clubs, only later being primarily employed by the players - and in fact, many agents still provide clubs with scout-like services in different countries. ${ }^{31}$ The difference will of course be that if it were the club that is engaging the agent, they would pay the required fee, whereas otherwise it would be the player (unless the club still pays the agent fees on the player's behalf, which is often the case in practice). Yet, from an economic perspective that does not necessarily play a major role. Given the contractual relationships between all parties involved, the Coase theorem teaches that the optimal allocation would result, no matter who pays the fee to the agent. ${ }^{32}$ If it were the player rather than the club who pays the agent (for example to arrange the transfer), the amount of the fee paid could be passed on to the club via the negotiated salary and/or other contractual benefits for the player.

Summarizing, the function of a sports agent seems to be based on well-established economic rationales for involving an intermediary in situations where the agent can reduce information and transaction costs. In that respect, the reasons for involving an intermediary are not different than in other branches where intermediaries are involved. Given these economic justifications for involving agents, the question that then arises is why there would be a need to regulate sports agents.

\section{The need to regulate the profession of sports agents}

\subsection{Background}

In the case of football, in conjunction with the intensifying involvement of agents in the football industry, and the

\footnotetext{
31 On the modern-day scouting networks developed by some agents, see notably Poli 2010.

${ }^{32}$ Coase 1960.
} 
concerns it gave rise to (with large amounts of money being received by agents, sometimes in the form of illicit payments ${ }^{33}$ ), FIFA decided to begin regulating the occupation in the 1990s, starting with access to the profession itself, with the adoption of Players' Agents Regulations in $1991 .{ }^{34}$ In an effort to bring football agents under FIFA's jurisdiction, these regulations required aspiring football agents to hold a compulsory FIFA agents' licence, conferred upon successful completion of an interview process, as well as satisfaction of certain ethical conditions, not to mention financial guarantees. In addition, FIFA has also introduced rules governing the exercise of the profession, including on matters relating to remuneration and conflicts of interest. The latest incarnation of these rules are the FIFA Regulations on Working with Intermediaries of $2015 .{ }^{35}$ Furthermore, as we will see in the next section, in different countries one can encounter rules regulating access to and/or the exercise of the profession of football agents at national level which, depending on the country in question, may be of a public as well as private nature. This has given rise to questions concerning the appropriate level of regulation, not to mention what the legal nature and content of the applicable regulations should be. Yet, even prior to entering into this discussion, the question arises as to whether there is actually a need to regulate the profession of sports agents at all. Certainly there are those who would take the view that contractual relations between private parties are in principle not a matter necessitating regulatory intervention, and should instead be left to the parties themselves to regulate by means of their contract, subject of course to existing rules and principles of general mandatory law. Why, then, has it been considered necessary by FIFA, and indeed national football associations and even legislatures, to regulate the provision of agency services to athletes, in terms of who can offer those services and under what conditions? ? $^{36}$

\subsection{Economic rationale}

From the perspective of the economic theory of regulation, a number of reasons to regulate professional services

\footnotetext{
33 See Rossi 2019, p. 134.

34 FIFA Players' Agents Regulations 1991.

35 FIFA Regulations on Working with Intermediaries 2015.

36 Apart from being discussed by renowned sports law scholars such as Parrish and Lindholm (see Parrish et al. 2019), this question has also been addressed by the EU General Court (at the time the European Court of First Instance) in its well-known judgment in Piau; case T-193/02 Laurent Piau v Commission of the European Communities [2005] ECR II-209 - where the Court considered (and ultimately affirmed) the legitimacy of FIFA's regulation of football agents from the perspective of EU competition law. However, this contribution will focus on this question from a law and economics perspective.
}

have been advanced, and some of those arguments can also explain why a need to regulate the profession of sports agents might be felt. ${ }^{37}$ What type of regulation these arguments would support, and whether/in what way these should extend to access to the profession as well as conduct of the activities of sports agents, is another matter-and one to which we shall return in the next section. At the fundamental level, though, there do exist possible justifications, and particularly economic justifications, for intervening especially in the athlete-agent relationship, rather than leaving it almost entirely to the parties themselves to determine with whom they wish to contract and subject to what terms.

The most likely candidate in terms of economic justifications for regulatory intervention is connected to the main reason why agents are needed by players in the first place, namely the existence of information asymmetries in player transfer and employment dealings. As regards their more ancillary managerial and advisory functions, agents serve to reduce information and transaction costs and the risk of harm or negative externalities is relatively low, meaning there is less need for regulation. However, when it comes to their role in player transfers and contract negotiations, this may be different. As was explained in the preceding section, most players have relatively limited knowledge of the transfer market and employment conditions as compared with clubs, and they therefore employ agents to offset this imbalance (at least to some extent), as agents (or at least competent ones) have significantly greater knowledge of the bargaining process and the salaries of other players. For this same reason, however, the relation between agents and their clients is obviously also characterized by asymmetric information. Markets for professional services are usually characterized by information asymmetry between professionals and clients. ${ }^{38}$ Generally speaking, there are two main reasons for the existence of this information asymmetry: firstly, professional services generally involve application of the professional's human capital in order to judge individual cases and, secondly, evaluation of the quality of the service itself may be very difficult. ${ }^{39}$ The use of the professional service also does not occur on a regular basis, as a result of which repeat interactions only have limited impact. Professional services are experience goods, meaning that the quality can only be determined after the service has been used. ${ }^{40}$ Information asymmetry can give rise to two different problems.

One such problem is that of 'adverse selection'. It is the famous problem analysed by Akerlof: If clients cannot

\footnotetext{
${ }_{37}$ See for example Philipsen 2007, pp. 112-150.

38 Philipsen 2007, p. 114.

39 Arruñada 2006, p. 52.

40 The concept was introduced by Nelson 1970 and see Philipsen 2007, p. 114.
} 
evaluate the quality of professional services, professionals have no incentives to provide high-quality services. As a result of the information asymmetry, they cannot signal relative differences in the quality of their services. ${ }^{41}$ Instead, the agents may be inclined to mislead the principal by overstating their competence, which they might do in order to persuade the principal to engage them as their representative, and/or to demand higher fees for their services. This theoretical possibility is predicated on the presence of information asymmetry between the principal and the agent, since the former lacks the knowledge to be able to evaluate the expertise of the agent, and the information to be able to assess the quality of services provided. ${ }^{42}$ As a result, there is the risk that the principal might contract with an agent who is not actually capable of performing the services the principal requires, and that even after contracting the principal would not be in a position to determine whether or not this is the case. Furthermore, this could lead to more widespread market failure because, in such a market, "the potentially good quality sports agent does not have the incentive to be a good quality sports agent", with the possible consequence that "[t]he quality will decrease to the point, where all the sports agents have the same low quality services". ${ }^{43}$ Adverse selection in the market of sports agents can give rise to the situation where bad professionals (or 'quacks') drive those who provide high quality services out of the market, as players cannot recognize high-quality services. Some form of quality regulation might then be needed to convert the market outcome of low quality and low price into one with a higher quality and a reasonable price. ${ }^{44}$

In addition, and related to this, there is the so-called moral hazard problem. ${ }^{45}$ This is where the agent does not behave fully in the interest of the principal, given the principal's inability to properly evaluate-or indeed even to monitor-the agent's efforts. ${ }^{46}$ This therefore also implies that asymmetric information between the agent and their client must exist, but not only; it is dependent on the pre-condition of a conflict of interest on the part of the agent as well. A conflict of interest for the agent may arise because, while the agent is acting on behalf of the player in seeking to achieve the player's career and financial objectives, the sports agent wishes to attain their own objectives and maximize their own profits at the same time, which do not perfectly align with those of the player, notwithstanding the fees being paid by the player for the agent's services. For instance, a sports

\footnotetext{
41 Akerlof p. 1970.

42 See Smienk 2009, p. 70, 87.

43 Ibid.

${ }^{44}$ Philipsen 2007, p. 114.

45 Ibid.

46 See Smienk 2009, p. 70, 84.
}

agent might derive greater personal benefit from concluding an agreement with a certain club and/or at a certain point in time than the player whom they represent. And the agent may be incentivized to prioritize their own interests, since the agent is not exposed to the risk of a bad deal being made between the player and a club, or at least not in the case of an individual transaction. In other words, "[t]he sports agent can earn money by making a good deal, but cannot lose any money (no risk involved). The risk of the failure of a contract is born [sic] by the athlete (principal). It could lead to more risk taking by the sports agent". ${ }^{47}$

Whether information asymmetry exists in the market of sports agents and whether this can therefore constitute a justification for regulation is an empirical matter. One has to be careful in making generalizations and always consider the specific characteristics of the market under review. ${ }^{48}$ However, given the nature of the sports market and the fact that the clients (players) are certainly no professionals with respect to the transfer market, nor with respect to the other services they require from their agent, there is indeed a serious risk of an information asymmetry and therefore potentially a need for regulation to remedy this problem.

Economic theory also advances other arguments for regulation, which may, however, be less applicable in the case of sports agent. One other possible public interest justification for regulation is the presence of negative externalities. ${ }^{49}$ Externalities could arise if the quality of the services rendered by sports agents is so poor that it affects third parties. Although one could theoretically imagine situations where the bad quality of services by an agent not only affects the player but also the acquiring club and potentially third parties (like fans and supporters), it is not clear that there is an eminent threat of negative externalities that could not be internalized through other means. After all, if the services performed by the agent were so bad that others (such as the acquiring club) would suffer, one would imagine that they would (via Coasean bargaining) negotiate in order to remedy the externality. Of course that assumes that transaction costs are low, though, which may not always be the case. If there is evidence of a serious risk of negative externalities, quality regulation and liability rules could be prescribed to increase the quality of professional services. ${ }^{50}$

Finally, restrictions of competition are always mentioned as a potential market failure that could justify regulation. One could theoretically imagine a cartel-like behaviour between sports agents, but there is no direct empirical evidence supporting this hypothesis. Moreover, if there were

\footnotetext{
47 See Smienk 2009, p. 70, 86.

48 Philipsen 2007, p. 115.

49 Ogus 1994, pp. 18-19.

${ }^{50}$ Philipsen 2007, p. 115.
} 
serious restrictions of competition, the legal 'solution' would typically be the application of competition law and not necessarily the introduction of professional regulation. ${ }^{51}$

These arguments (information asymmetry, negative externalities, restrictions of competition) are the market failures that are considered the classic arguments in favour of regulation, assuming that regulation would be drafted in the public interest. There is, however, an alternative explanation for the emergence of regulation, referred to as the private interest approach. This has its origins in both public choice theory ${ }^{52}$ as well as in the economic theory of regulation that emerged from Chicago. ${ }^{53}$ According to this view, rent-seeking interest groups will seek regulation to provide them benefits (rents). Regulation will be provided by utility maximizing politicians in exchange for support, more particularly with elections. High information costs for the public and low transaction costs for the interest group are important criteria for effective lobbying. ${ }^{54}$ Regulation is in that perspective viewed as a method for erecting entry barriers for newcomers, thus raising profits for the firms currently active on the market. ${ }^{55}$

If both perspectives are combined, it means that there could be public interest reasons for regulation (for example information asymmetries), but that there is always a danger that regulation is imposed to serve the private benefits of a particular interest group. Moreover, even when information asymmetries may constitute a (public interest) justification for regulation, the question still arises as to what type of regulation is effectively applied with respect to sports agents and whether that regulation is proportional to cure the market failure caused by information asymmetry in an effective manner.

\section{Options for regulation of the profession of football agents}

\subsection{Background}

The peripheral position of sports agents implies that their interests are likely to be quite different from those of other stakeholders in the sports industry-but it also gives rise to a significant regulatory conundrum. Whereas the law governing athletes, sports entities and national and international sporting endeavour is founded (at least primarily) on rules of private origin, the profession and activities of sports agents

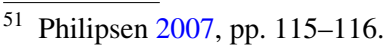

${ }^{52}$ See inter alia Buchanan and Tullock 1962.

53 See in that respect inter alia Peltzman 1976; Posner 1974 and Stigler 1971.

54 Olson 1971.

55 Stigler 1971.
}

do not fit neatly within this system of private regulation. Private regulation - that is, private rule-making and normsetting by organizations based on private law constructs, and particularly contractual bases_-plays a central role in national and international sports. Indeed, while sporting activities are governed also by rules of public law (such as tax law, administrative law and even criminal law), private regulation is said to "form the backbone of sports law." 56 The same is not necessarily true of the law governing sports agents, though. Given that the activity of sports agents is not a sporting one per se, it follows that it may be possible for agents to exercise their profession without being subject to the relevant rules and regulations (if any) of the governing bodies of the sports in which they are active. Equally, for the same reason, it may be that access to and/or performance of the profession of sports agent are regulated by certain laws of the state (and particularly labour laws applicable to agency, as well general contract and tort laws) that are not necessarily applicable to the actors with whom they interact.

When it comes to the football agents industry, it was already mentioned that the international governing body of football, FIFA, has created a regime regulating the occupation of football agents. As in the case of other sports governing bodies, FIFA derives its regulatory authority from a chain of contractual agreements with national football associations, which are members of FIFA, through football clubs and ultimately football players. ${ }^{57}$ In order to be admitted to the professional football order and take part in the leagues and competitions organized by their national association, as well as their continental confederation (of which there are six in the world, provided for in FIFA's statutes), football clubs and, in turn, the players who join them are required to agree to be subject to the regulations promulgated by these governing bodies, and to abide by them accordingly. By doing so, they also submit themselves to the disciplinary and sanctioning powers of their national association and FIFA; and if they refuse or fail to do so, they are liable to be excluded from exercising their profession. Being sports governing bodies, however, neither FIFA nor its member associations have a pre-existing contractual relationship, whether direct or indirect, with football agents. Any regulations adopted by such bodies in respect of agents are applicable to - or, more precisely, enforceable against—-them only to the extent that the agent submits to the FIFA or national regulatory regime in the first place. Of course, the possibility of enforcing regulations against the football players and clubs who use agents that do not comply with those regulations remains, but the point is that FIFA does not have any direct authority over football agents, and the same is

\footnotetext{
$\overline{56}$ Rey 2007, p. 75.

${ }^{57}$ On FIFA's organization and powers, see the FIFA Statutes 2020.
} 
true of football associations at national level. It should also be added that the reason why the regulations of national football associations are of relevance to football agents is because, in implementing and enforcing the minimum requirements and standards contained in the FIFA regulations, as they are contractually bound to do, national member associations are entitled to go beyond them. ${ }^{58}$ Conversely, continental confederations, such as the Union of European Football Associations (UEFA) in Europe, are not members of FIFA, though membership of a confederation constitutes a pre-requisite for membership of FIFA. Their primary role is to represent their national member associations, as well as to organize and administer club (as well as international) competitions, including the regulation of those particular competitions-but their regulatory authority does not extend to the sport in general. ${ }^{59}$

In terms of public regulation, the legal framework of the regulation of the football agents industry is further complicated by the fact that, being a profession that is inextricably linked to the labour market for players and contracts of employment, there may be national employment laws and/or contract laws specifically applicable to the activities of football agents. This depends on the country in question, with some state legislatures having laid down rules governing the conduct of agency activities, if not even access to the profession itself, while others may only have judge-made rules regulating only the exercise of the profession, and others still having no special rules at all. ${ }^{60}$ On the other hand, while the thought may arise in relation to football agents operating in Europe, European Union law does not actually form part of the mosaic of regulation that we have just briefly depicted, largely because the EU has only a circumscribed competence in both the area of sports law and that of labour law. As regards the former, the very limited competence that does exist was only introduced after the entry into force of the Lisbon Treaty in 2009, and merely enables the EU to 'contribute to the promotion of European sporting issues. ${ }^{, 61}$ Meanwhile, in the case of the latter, the EU fundamentally has the competence to "take measures to ensure coordination of the employment policies of the Member States, in particular by defining guidelines for these policies', ${ }^{62}$ and to date it has not taken any such measures with respect to national policies concerning football agents. It is true that the EU could

\footnotetext{
58 See Art. 1(3) of the current FIFA Regulations on Working with Intermediaries 2015.

59 On UEFA's organization and powers, as well as its relationship with FIFA, see the UEFA Statutes 2020.

${ }^{60}$ For a concise overview of different national legal requirements regulating agents in a range of European countries, see Parrish et al. 2018.

61 Treaty on the Functioning of the European Union, Art. 165(1).

62 Treaty on the Functioning of the European Union, Art. 5(2).
}

potentially take action in this area on the basis of Article 114 TFEU, which allows for the adoption of approximation measures aimed at improving the functioning of the internal market: While this possibility may exist, though, the EU has not availed itself of it to date. ${ }^{63}$

Thus, as far as the level of regulation is concerned, the established options for regulation of the profession of football agents essentially lie at a combination of both the international and national level on the private side, and at the national level on the public side. ${ }^{64}$ In the present section, we will outline some of the regulatory approaches that have been taken at these different levels, including the legal nature as well as the substantive content of the regulations that have been adopted. We will begin by explaining the current approach of FIFA at the international level, not to mention how this has evolved over time, before zooming into certain national jurisdictions. Our focus in this respect will be on the European context, this being the continent in which the biggest and highest-grossing professional leagues are located. We will then discuss different regulatory options that could be considered in light of insights from law and economics scholarship.

\subsection{Private standards and international regulation}

As was indicated previously, FIFA first began regulating the football agents profession in the early 1990s, with the creation of the FIFA Players' Agents Regulations 1991, which introduced a FIFA agents' licence that would be compulsory (at least from FIFA's perspective) for the purposes of obtaining access to the profession. Thereafter, persons who wished to act as representatives of footballers and football clubs would in principle have to be in possession of this licence in order to be entitled to legitimately carry out that activity (with a few exceptions for qualified lawyers and players' relatives). Initially this licence was conferred primarily on the basis of an interview process; then, after revisions to the regulations in 1994 and 1995, such persons were required to successfully complete an examination assessing their technical competences (in terms of their knowledge of the sport as well as relevant rules and regulations). ${ }^{65}$ For the first ten years of this new system's existence, the licence was conferred centrally by FIFA itself. Subsequently, following a

\footnotetext{
${ }_{63}$ Indeed this possibility is acknowledged in the literature (see for example Parrish et al. 2019, p. 12) and is clearly a point for further research. However, the question of whether the EU could - and, if so, should - intervene goes beyond the scope of this contribution.

${ }^{64}$ Although relevant international instruments of public law do also exist, such as notably the Private Employment Agencies Convention of the UN's International Labour Organization (Convention C181 concerning Private Employment Agencies of 19 June 1997).

${ }^{65}$ See further Rossi et al. 2016, p.115 ff.
} 
further revision of the regulations in 2001, players' agents needed to obtain the licence directly from the respective member associations, which for their part were under the obligation to implement and enforce the FIFA regulations. ${ }^{66}$ By reserving access to the profession exclusively for those in possession of a FIFA licence, FIFA sought to extend its reach to these actors insofar as, once a licence was conferred, the licence-holder would be subject to the private standards on which the granting of the licence was conditional, and particularly ethical rules governing the relationship with their clients and the exercise of their activities. Infringements of these standards by licenced agents could be sanctioned, for instance by the imposition of a fine on the agent, if not the withdrawal of their licence altogether. ${ }^{67} \mathrm{In}$ addition, clubs and players could be subject to a number of sanctions if they engaged unlicensed agents to assist them in their dealings. ${ }^{68}$ And yet, notwithstanding these sanctions, a large majority of international football transfers continued to be conducted by unlicensed agents, ${ }^{69}$ who, being unlicensed, were not subject to the standards imposed by FIFA themselves.

As a result, the most recent reform of FIFA's regulations in 2015 saw the elimination of the compulsory licence and its replacement with a minimum registration requirement. This latest version of the regulations, renamed the FIFA Regulations on Working with Intermediaries (RWI), which is the version currently in force, therefore marked a notable departure from the previous system, inasmuch as it de-regulated the profession of football intermediaries (as football agents would henceforth be known). Instead of having to obtain a licence via an examination, persons wishing to become football intermediaries are now merely required to register with a competent national member association. ${ }^{70}$ This can be done by simply depositing with that association the representation contract that the intermediary concludes with a player and/or club, provided the association is 'satisfied that the intermediary involved has an impeccable reputation'. ${ }^{71}$ Then, once registered, such persons are again bound to abide by the standards in the FIFA regulations governing the conduct of the occupation (not to mention the general FIFA code of ethics, which prescribes a

\footnotetext{
${ }_{66}$ FIFA Players' Agents Regulations 2001, Art. 1.

${ }^{67}$ FIFA Players' Agents Regulations 1991, Art. 15.

68 See Rossi et al. 2016, p. 116.

69 By FIFA's own estimates, almost twenty years after the introduction of its licensing system, around $70 \%$ of international football transfers were still being conducted by unlicensed agents, as was also acknowledged by FIFA's member associations; see Ioannidis 2019, p. 154, 160, and also Rossi et al. 2016, p. 121.

70 See FIFA Regulations on Working with Intermediaries 2015, particularly Arts. 2(3) and 3.

${ }^{71}$ FIFA Regulations on Working with Intermediaries 2015, Art. 4.
}

range of rules of conduct ${ }^{72}$ ). Under the 2015 regulations, these include the duty to disclose earnings ${ }^{73}$ and actual or potential conflicts of interest (and in such circumstances to obtain the written consent of the parties before initiating negotiations) ${ }^{74}$ which can be sanctioned by national member associations. ${ }^{75}$ The RWI also set a benchmark for the level of remuneration of intermediaries, '[w]hile taking into account the relevant national regulations... and as a recommendation', namely $3 \%$ of the player's basic gross income in the case of an employment contract, or $3 \%$ of the transfer fee in the case of a transfer agreement. ${ }^{76}$ So, by lowering the basic entry requirements for persons to legitimately act as intermediaries (again, in the eyes of FIFA), the latest FIFA regulations reflect an attempt to bring more football agents within FIFA's - and hence FIFA's member associations'-private regulatory authority over the conduct of the occupation. This is not to say that this approach has not proved controversial. On the contrary, it has attracted much criticism, not least from agents licensed under the previous system, to the extent that FIFA is, at the time of writing, due to introduce another reform of its regulations, which could see a return to a licensing requirement. ${ }^{77}$ But it is clearly a different approach, which combines conduct regulation with a relatively low access requirement, rather than a relatively high one.

At any rate, it should also be remembered that those natural or legal persons who register with a FIFA national member association in accordance with the applicable regulations implemented by that association will be bound by any additional requirements that association may have adopted as well, bearing in mind the right of these associations to go beyond FIFA's minimum requirements in implementing and enforcing the standards in the 2015 regulations within their jurisdictions. This brings us to the matter of domestic private regulation, being especially the implementing rules of national football associations, with which persons wishing to be recognized as intermediaries in the given jurisdiction must register. And, in turn, it will also bring us to domestic public regulation, since these national implementing regulations are 'subject to the mandatory laws and any other mandatory national legislative norms' that apply to the national associations. ${ }^{78}$

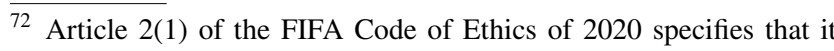
covers intermediaries among others.

${ }^{73}$ FIFA Regulations on Working with Intermediaries 2015, Art. 6(1).

${ }^{74}$ FIFA Regulations on Working with Intermediaries 2015, Art. 8(2).

75 FIFA Regulations on Working with Intermediaries 2015, Art. 9.

${ }^{76}$ FIFA Regulations on Working with Intermediaries 2015, Art. 7(3).

77 See Parrish et al. 2019, p. 4.

${ }^{78}$ FIFA Regulations on Working with Intermediaries 2015, Art. 1(2).
} 


\subsection{Private standards and domestic regulation}

As was just explained in the preceding subsection, national member associations of FIFA are required by the RWI to introduce domestic implementing regulations in order to give effect to the RWI's provisions. And given that these associations are entitled to impose additional and more stringent standards to those contained in the RWI, while at the same time being subject to national mandatory laws, one can encounter significant differences in the regulatory approaches adopted at national level.

In England, for example, the national member association, known simply as the Football Association (FA), implemented the RWI through the FA Regulations on Working with Intermediaries, which came into effect on 1 April 2015. These took over the RWI's minimum registration requirement for access to the intermediary profession, requiring agents to enter into a representation contract with the player or club 'prior to that Intermediary carrying out any Intermediary Activity on his or its behalf', ${ }^{79}$ and to lodge that contract with the FA 'within 10 days of being executed and in any event no later than at the time of the registration of a Transaction by the Association, ${ }^{80}$ after which the FA will apply a test of good character in order to assess the impeccable reputation of the agent. The FA regulations then add, however, a series of conditions applicable to the representation contract itself, as well as duties that intermediaries agree to by registering. When it comes to the contract itself, for an agreement with a player this is for example limited to a maximum duration of two years, ${ }^{81}$ and cannot be with a minor unless written consent is obtained from the minor's parent or legal guardian. ${ }^{82}$ And in terms of duties, there are additional provisions concerning conflicts of interest and duties of disclosure. As regards the former, intermediaries are for instance prohibited from having an 'interest' (e.g. a business or proprietary interest) in a club or in any player transfer compensation, as well as from offering any benefits or favours in return for preferential treatment by a club or player. ${ }^{83}$ In addition, an intermediary is only permitted to act for one party to a transaction, unless they comply with further requirements regarding consent for dual or multiple representation. ${ }^{84}$ As for the latter, intermediaries must disclose, among other things, any remunerated contractual or other arrangement that they may have with any player, club, club

\footnotetext{
79 FA Regulations on Working with Intermediaries 2015, Rule B1.

${ }^{80}$ FA Regulations on Working with Intermediaries 2015, Rule B3.

${ }^{81}$ FA Regulations on Working with Intermediaries 2015, Rule B10.

82 FA Regulations on Working with Intermediaries 2015, Rule B9.

83 See FA Regulations on Working with Intermediaries 2015, Rule E4-7.

${ }^{84}$ FA Regulations on Working with Intermediaries 2015, Rule E1.
}

official or manager, as well as any actual or potential conflict of interest they might have in relation to a transaction. ${ }^{85}$ Furthermore, on top of the FIFA benchmark for remuneration of 3\%, there are also other provisions regulating the means and recording of payments, as well as a requirement that any payment must be processed through the FA's clearing house. ${ }^{86}$ All of these regulations are enforceable by the FA, with any breach of the private standards contained therein to be 'dealt with in accordance with the Rules of The Association and...determined by a Regulatory Commission of the Association. ${ }^{87}$ The FA has the power to sanction the agent by means of a fine, a suspension or even a permanent ban. ${ }^{88}$

Thus, access to and the exercise of the intermediary profession in England is regulated predominantly by the FA through its own regulations which, in line with FIFA's RWI, provide for relatively low entry requirements, albeit in combination with stricter conduct regulation. Beyond these regulations, there are also certain national legal requirements regulating the activities of intermediaries, including particularly the common law of agency, which prescribes general private law duties of care, openness and good faith, as well as the rules laid down in some legislative instruments, such as the Fraud Act 2006 and the Bribery Act 2010. However, the overall regulatory approach in England is based on minimum requirements, which focus more on conduct of the profession (and especially on transparency) than on access to it, and public standards applicable to the profession are largely absent.

\subsection{Public standards and domestic regulation}

To take another example of domestic regulation, the picture in France is very different. While the French national football association, the Fédération française de football (FFF), has also adopted its own specific regulations applicable to football agents (the règlement FFF sur les agents sportifs), these regulations are in the main a reiteration of codified public laws governing sports agents that are set out in the Code du Sport, which has been in existence for many years already, and which primarily regulates the profession of sports agents in France. Apart from this, the FFF regulations merely supplement the codified law with some technical specifications. In fact, it is by virtue of these special public laws, which are laid down in a series of articles in the Code du Sport, that the RWI have not actually been implemented in France: On the contrary, the FFF has

\footnotetext{
${ }^{85}$ See FA Regulations on Working with Intermediaries 2015, Rule E8-10.

${ }^{86}$ See FA Regulations on Working with Intermediaries 2015, Rule C.

${ }^{87}$ FA Regulations on Working with Intermediaries 2015, Rule F1.

${ }^{88}$ See Parrish et al. 2018, p. 49.
} 
formally informed FIFA that the RWI are not applicable in the French jurisdiction. ${ }^{89}$ Fundamentally, this is because the public regulations governing the profession of sports intermediaries are mandatory laws of public order, which 'trump' rules of private origin, as is recognized in the FIFA RWI themselves. Furthermore, these public requirements are stringent in their content (not to mention their scope, since they cover all sports and not just football), meaning they set a standard that goes considerably beyond the minimum requirements established in the RWI. Specifically, the mandatory French legislation "requires that the agent (i) holds an official licence to operate a business as a sports agent (the conditions for obtaining which are very strictly detailed); (ii) comply with certain good practice rules; and, (iii) submit to the disciplinary procedures of the sports association." ${ }^{90}$ In other words, the regulatory approach in France combines a rather high access requirement with rules of conduct, by requiring agents to obtain a licence, which is issued by the FFF Sports Agents Commission, upon successful completion of a written examination testing the applicant's knowledge of legal and sporting rules. ${ }^{91}$ On top of this, a number of rigorous transparency and reporting obligations as well as conflict of interest-related requirements are imposed on licensed agents, who risk disciplinary fines as well as temporary suspension or permanent revocation of their licence if they do not comply. ${ }^{92}$ Meanwhile, unlicensed agents who carry on the occupation of sports agency regardless can be held criminally liable, with punishment including not just a hefty fine of at least $€ 30,000$, but even two years imprisonment — and this may be accompanied by a temporary or permanent ban on exercising the profession. ${ }^{93}$

It is apparent, therefore, that the French regulatory approach stands in stark contrast to that taken in England, as it is derived predominantly from rules of public origin, which are concerned with access to the profession as much as the exercise of it, and are based on high principles and standards as regards both of these aspects.

\subsection{Law and economics perspective}

The regulation of sports agents has various interesting features from an economic perspective. As the overview showed, there are various regulations at different levels, both at the international level (FIFA) as well as at the national

\footnotetext{
${ }^{89}$ See Parrish et al. 2018, p. 58.

90 Parrish et al. 2018, p. 57.

91 Code du Sport, Art. L.222-7.

92 And some of these requirements are significantly more restrictive than those provided by the RWI, such as Article L.222-17 of the Code $d u$ Sport, which prohibits dual representation.

93 Code du Sport, Art. L.222-21.
}

level. There is, moreover, a combination of private standards and public regulation.

Looking first at the contents of the regulatory obligations, there is apparently regulation of the entry into the profession via different instruments. A traditional instrument used to regulate services by professionals is licencing. From a public interest perspective, licencing could, in theory, raise the average quality of professionals and could therefore solve problems of adverse selection, moral hazard or negative externalities. ${ }^{94}$ However, there is always a danger that if licencing also raises prices, substitution would take place to cheaper alternatives, do-it-yourself remedies or services offered on the black market. ${ }^{95}$ The overwhelming empirical evidence concerning the effects of licencing is that it does indeed raise profits and prices of the professionals. ${ }^{96}$ Also in the case of sports agents, it is questionable that the mere requirement of a licence would as such increase quality and cure the information asymmetry and adverse selection problems. Most empirical studies find that the quality of services is not affected by licencing or business practice restrictions. ${ }^{97}$ The nature of the licencing requirements for sports agents also seems to be such that it can at best exclude the crooks, but it is doubtful whether for example the compulsory licence, as it was created by FIFA (in the Regulations 1991), would as such increase the quality of their services.

There is another consideration that should be taken into account: The private interest theory has pointed out that politicians, bureaucrats and incumbent professionals all derive benefits from the administrative requirements set out in licencing systems. ${ }^{98}$ According to a classic article by Moore, the main purpose of licencing is to create barriers to market entry for newcomers. ${ }^{99}$ Also with respect to sports agents, the licencing required by FIFA, but especially the French legislation (with very strictly detailed conditions) do create barriers to market entry. It is, moreover, questionable whether licencing is indeed necessary to cure the market failure in the relationship between the sports agent and the player (which would be a public interest argument for licencing), or whether it merely serves the interests of the incumbent sports agents. An alternative, equally identified in the literature, is certification. That refers to the protection of a title. Those who do not have the certification may not use the protected title. The danger of a licencing system is that, by creating barriers to market entry, competition could be more restricted than necessary. As there is no tension

\footnotetext{
${ }^{94}$ Philipsen 2011, p. 207.

95 Ibid.

${ }^{96}$ Philipsen 2007, p. 121.

97 Ibid.

98 See Ogus and Zhang 2005, pp. 138-141.

99 Moore 1961
} 
between competition law and certification, economists generally argue that certification is superior to licencing, provided that it can adequately deal with the market failure it is supposed to solve. ${ }^{100}$ Certification of sports agents would cure the information asymmetry as it conveys information about human capital investments, such as a particular training level, but it does not have the same type of restrictions on entry as licencing does. ${ }^{101}$ In a way, the changes in the FIFA Regulations in 2015, whereby the compulsory licence was eliminated and replaced with a minimum registration requirement, could be seen as a move from licencing to a form of certification. ${ }^{102}$ Football agents are now merely required to register with a competent national member association, which has considerably lower barriers to market entry than a licencing regime. That 2015 reform could therefore be supported on public interest grounds although, as we will argue below, it may equally be explained as serving the interests of FIFA itself.

In addition to entry regulation, professionals are also often subject to quality regulation, providing minimum regulation of conduct. Quality regulation limits entry into the market less than licencing, of course depending upon the nature of the conduct regulation. The question especially arises whether the conduct regulation is justified (in order to remedy the market failure of information asymmetry) and proportional. ${ }^{103}$ One specific type of conduct regulation is the regulation of prices and fees. Those types of regulations severely limit competition in the market and are usually not considered as a proportional remedy for the market failure. ${ }^{104}$ Far-reaching conduct regulation can equally be found concerning the football agents. The RWI of the FIFA even sets a 3\% recommended limit in case of a transfer. The domestic regulations we discussed also provide regulations concerning payment on top of the FIFA benchmark. Some of the conduct regulation, for example the (FIFA) duty to disclose earnings, the (English) duty to disclose conflicts of interests and the (French) rules of conduct concerning transparency and reporting obligations, could be justified from a public interest perspective as rules that remedy information

\footnotetext{
$\overline{100 \text { Philipsen }}$ 2011, pp. 205-206.

101 Shapiro 1986.

102 Again, the term 'certification' here is used from the perspective of law and economics to denote some form of protection of title, rather than in a legal sense.

103 Philipsen 2007, p. 118.

104 Philipsen 2007, pp. 118-119. It is true that, as Philipsen also acknowledges, there has been discussion in the European context of the extent to which private or public regulations of this kind could themselves constitute an infringement of EU competition law or free movement law (particularly in relation to the legal and accountancy professions). Indeed this is certainly another angle from which this issue may be tackled, beyond the perspective of economic theory of regulation that is discussed in this contribution.
}

asymmetry as well as adverse selection. Conflicts of interests may be a serious problem, which players could not always detect and which could seriously harm their interests. However, the question arises whether in addition to these (justified) strict rules of conduct it is equally necessary to have strict entry regulation into the profession. That combination may be disproportional, as heavy entry requirements (especially in France) do not necessarily add anything, as far as quality of services is concerned, in addition to the conduct regulation. Especially, the regulation of fees is problematic as it seriously limits competition between agents. The fee regulation moreover does not take into account the heterogeneity between various transfer agreements, which may justify different arrangements between the agent and the player than the recommended $3 \%$ rule of FIFA.

There is one particular aspect which has less to do with the contents of the regulation, but more with the organization creating the rules, being that in this domain one can apparently recognize an important role played by private standards or self-regulation. In the literature an argument has been made in favour of self-regulation by Miller, contending that private parties can have more or better information on quality and risks than the government, or could acquire this information at lower costs. ${ }^{105}$ Government authorities may indeed lack information to regulate the services provided by sports agents. Self-regulatory bodies are also supposed to have the advantage of being able to regulate at lower costs. ${ }^{106}$ A major danger with self-regulation is obviously that it could serve the private interest of the profession, rather than the public interest. Professions may generally lack appropriate incentives to control and enforce quality standards and, in practice, professional organizations rarely enforce the self-regulatory rules in an adequate manner. ${ }^{107}$ It is in that respect interesting that the primary rule-setter in this domain is the worldwide organisation FIFA. But FIFA apparently was confronted with a large number of transfers taking place through unlicensed agents and hence not subject to the FIFA standards. That was one of the principal reasons for FIFA to change the regulations in 2015 from a licencing to a registration model. ${ }^{108}$ By lowering the entry requirements, FIFA may have guaranteed that more transfers came within its authority. Even though, as we just mentioned, this reform could be explained on public interest grounds, it could equally be considered as a means to enlarge the scope of FIFA's competence and hence its interest as well. At the same time, it is also understandable from an economic perspective that FIFA is currently planning a return

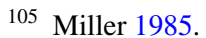

106 Philipsen 2011, p. 210.

107 Van den Bergh and Faure 1991.

108 Ioannidis 2019, p. 154, 160; Masteralexis 2016, p116.
} 
to a licencing system, insofar as with the relaxation of entry requirements comes the possibility of market failures related to abuse and loss of control. As far as domestic regulation is concerned, different models apply whereby, as we showed, England uses private standards, whereas France largely relies on public regulation. The private standard approach in England is merely based on minimum requirements, which focus on conduct regulation and transparency rather than access to the profession and which are thus largely in line with the public interest explanation of regulation. The French regulation in contrast goes much further by combining a strictly detailed licencing with rules of conduct. Although further research would be needed to explain these differences in greater detail, it seems as if the intermediaries in France have been more successful in protecting their profession by securing heavy entry (licencing) requirements in combination with rules of conduct via public regulation (the Code $d u$ Sport). This can be explained by the private interest theory, which maintains that a profession with strong political power ${ }^{109}$ will lobby the government to obtain mandatory licencing and to criminalize the unlicensed exercise of the profession (as it is the case in France). The heavy regulations in France are therefore likely to be the result of successful lobbying by the interest groups of sports intermediaries, but can hardly be explained as curing a market failure. Interestingly, in this particular case, the private standard in England is more in line with the public interest than the public regulation in France.

\section{Conclusion}

In this paper, we tried to introduce the intriguing world of sports agents and sporting transfers to law and economics and to equally use regulation theory to examine some of the regulations applicable to sports agents. The activities performed by sports agents have a large economic and societal impact and already for that reason merit scholarly attention. We showed that the theory of regulation can provide a framework for analysing the activities and services performed by sports agents.

As the relationship between a sports agent and a player could be characterized as one with information asymmetries, there can certainly be a public interest reason to regulate sports agents, although there is always the danger that the public interest argument for regulation is abused by creating too far-reaching regulations that mostly serve the private interests of the particular profession. This may indeed be the case, especially when addressing the regulation of

109 And a narrowly defined interest (single-issue oriented), and thus with low transaction costs. sports agents in France. The regulations are of a complicated nature, as the general framework is provided by the FIFA Private Standards and the minimum requirements established in the RWI, but national implementation takes place, in some countries via yet again private standards (England) and in others via public regulation (France).

We showed that, as is often the case with the regulation of professions, public interest arguments may justify some form of regulation, but in particular cases private interests may drive regulation to become disproportional and to either exclude competition (via price regulation) or to impose an unnecessary limit on entry to the profession (by means of strict licencing requirements). Those rules are not always proportional to cure the (information) problem at hand. There can be a valuable collaboration between law and economics and sports law. Sports law consists of a variety of interesting rules which provide many possibilities for fruitful law and economics research. At the same time, the economic approach to sports law and, in this particular case, to the regulation of sports agents, can provide new and interesting insights, for example concerning the effects and effectiveness of particular types of regulation.

There are undoubtedly many other ways in which further research into this fascinating domain of sport transfers and the role of the agents could be expanded. We briefly addressed the hybrid nature of the regulations, demonstrating multilevel governance (between FIFA and domestic regulation) as well as hybrid regulation (combining private and public standards). By merely examining two countries (England and France), we already highlighted substantial differences in regulatory intensity. It would be interesting to expand the research into, on the one hand, an analysis of the nature of the regulation in other EU Member States as well and, on the other hand, a further examination of the relationship between the nature of the regulation of sports agents and the effects on the transfer market (for example concerning the fees charged, but also the volume of transfers taking place). Those and other questions certainly merit further research.

Acknowledgements We are grateful to participants of the Annual Conference of the European Association of Law and Economics (EALE) in Paris that took place online in 2020, as well as to the participants of a joint METRO Institute for Transnational Legal Research/Maastricht European Private Law Institute online seminar in the same year, for useful comments on an earlier version of this paper.

Authors' contributions W.B. conceived of the original idea and investigated the practical and legal aspects of the topic. M.F. developed the economic theory applied to the practice and the law. Both authors contributed to and wrote the final manuscript.

Funding Not applicable.

Availability of data and material Not applicable. 
Code availability Not applicable.

\section{Declarations}

\section{Conflicts of interest Not applicable.}

Open Access This article is licensed under a Creative Commons Attribution 4.0 International License, which permits use, sharing, adaptation, distribution and reproduction in any medium or format, as long as you give appropriate credit to the original author(s) and the source, provide a link to the Creative Commons licence, and indicate if changes were made. The images or other third party material in this article are included in the article's Creative Commons licence, unless indicated otherwise in a credit line to the material. If material is not included in the article's Creative Commons licence and your intended use is not permitted by statutory regulation or exceeds the permitted use, you will need to obtain permission directly from the copyright holder. To view a copy of this licence, visit http://creativecommons.org/licenses/by/4.0/.

\section{References}

Akerlof G (1970) The market for lemons: quality, uncertainty and the market mechanism. Quart J Econ 85:488-500

Arruñada B (2006) Managing competition in professional services and the burden of inertia. In: Ehlemann CD, Atanasiu I (eds) European competition law annual 2004: the relationship between competition law and (liberal) professions. Hart Publishing, Oxford, pp 31-71

Buchanan JM, Tullock G (1962) The calculus of consent. University of Michigan Press, Ann Arbor

Coase RA (1960) The problem of social cost. J Law Econ 3:1-44

Crandall J (1981) The agent-athlete relationship in professional and amateur sports: the inherent potential for abuse and the need for regulation. Buffalo Law Rev 30:815-849

De Marco N, Lowen D (2018) Football intermediaries, regulation and legal disputes. In: De Marco N (ed) Football and the law. Bloomsbury Professional, London, pp 213-237

Faure M, Finsinger J, Siegers J, Van den Bergh R (eds) (1993) Regulation of professions. A law and economics approach to the regulation of attorneys and physicians in the US, Belgium, The Netherlands, Germany and the UK. Maklu, Antwerp

Galanter M (1974) Why the 'haves' come out ahead: speculations on the limits of legal change. Law Soc Rev 9(1):95-160

Ioannidis G (2019) Football intermediaries and self-regulation: the need for greater transparency through disciplinary law, sanctioning and qualifying criteria. Int Sports Law J 19:154-170

KEA - CDES (2013) Study on the economic and legal aspects of transfers of players. https://ec.europa.eu/assets/eac/sport/library/docum ents/cons-study-transfers-final-rpt.pdf. Accessed 15 January 2021

Magee J (2002) Shifting balances of power in the new football economy. In: Sugden J, Tomlinson A (eds), Power games: a critical sociology of sport, Taylor \& Francis, Abingdon, pp 216-239

Masteralexis L (2016) Regulating player agents. In: Barry M, Skinner J, Engelberg T (eds) Research handbook of employment relations in sport. Edward Elgar, Cheltenham, pp 99-123

Miller JC (1985) The FTC and voluntary standards: maximizing the net benefits of self-regulation. Cato J 4:897-903
Moore TG (1961) The purpose of licencing. J Law Econ, 93-117

Nelson P (1970) Information and consumer behavior. J Polit Econ 78:311-329

Ogus AI (1994) Regulation: legal form and economic theory. Clarendon Press, Oxford

Ogus A, Zhang Q (2005) Licencing regimes East and West. Int Rev Law Econ 25(1):124-142

Olson M (1971) The logic of collective action. Harvard University Press, Cambridge

Parrish R et al. (2018) Promoting and supporting good Governance in the European Football Agents Industry, National Association Intermediary Regulations. https://www.edgehill.ac.uk/law/files/ 2019/10/National-Associations-Report.pdf. Accessed 15 January 2021

Parrish R et al. (2019) Promoting and supporting good governance in the european football agents industry, Final Report. https://www. edgehill.ac.uk/law/files/2019/10/Final-Report.pdf. Accessed 15 January 2021.

Peltzman S (1976) Toward a more general theory of regulation. J Law Econ, 211-240

Philipsen NJ (2007) The law and economics of professional regulation: what does the theory teach China? In: Eger T, Faure M, Naigen $\mathrm{Z}$ (eds) Economic analysis of law in China. Edward Elgar, Cheltenham, pp 112-150

Philipsen N (2011) Professional licencing and self-regulation in Europe and China: a law and economics perspective. In: Faure M, Zhang $\mathrm{X}$ (eds), Competition policy and regulation. recent developments in China, the US and Europe, Edward Elgar, Cheltenham, pp 205-237

Poli R (2010) Le marché des footballeurs: Reseaux et circuits dans l'économie globale. Peter Lang, Bern

Posner R (1974) Theories of economic regulation. Bell Journal of Economics: $335-358$

Rey JM (2007) Spain. Int Sports Law J 1(2):75-81

Rossi G (2019) Agents and intermediaries. In: Chadwick S et al (eds) Routledge handbook of football business and management. Routledge, London, pp 131-143

Rossi G et al (2016) Sports agents and labour markets: evidence from world football. Routledge, London

Schimke M (2007) Germany. Int Sports Law J 1(2):58-65

Semens A, Pendlebury A (2013) Sports agents and intermediaries. In: Chadwick S, Beech J (eds), The business of sports management, Pearson, Harlow, pp 527-544

Shapiro C (1986) Investment, moral hazard and occupational licencing. Rev Econ Stud 53:843-862

Shropshire K, Davis T (2008) The business of sports agents. University of Pennsylvania Press, Philadelphia

Smienk M (2009) Regulation in the market of sports agents: or no regulation at all? Int Sports Law J 3(4):70-93

Stigler G (1971) The theory of economic regulation. Bell J Econ, 3-21

Van den Bergh R, Faure M (1991) Self-regulation of the professions in Belgium. Int Rev Law Econ 11:165-182

Publisher's Note Springer Nature remains neutral with regard to jurisdictional claims in published maps and institutional affiliations. 